\title{
Development and Initial Validation of the Activity Patterns Scale in Patients With Chronic Pain
}

Citation for published version (APA):

Esteve, R., Ramirez-Maestre, C., Peters, M. L., Serrano-lbanez, E. R., Ruiz-Parraga, G. T., \& LopezMartinez, A. E. (2016). Development and Initial Validation of the Activity Patterns Scale in Patients With Chronic Pain. The Journal of Pain, 17(4), 451-461. https://doi.org/10.1016/j.jpain.2015.12.009

Document status and date:

Published: 01/04/2016

DOI:

10.1016/j.jpain.2015.12.009

Document Version:

Publisher's PDF, also known as Version of record

Document license:

Taverne

Please check the document version of this publication:

- A submitted manuscript is the version of the article upon submission and before peer-review. There can be important differences between the submitted version and the official published version of record.

People interested in the research are advised to contact the author for the final version of the publication, or visit the DOI to the publisher's website.

- The final author version and the galley proof are versions of the publication after peer review.

- The final published version features the final layout of the paper including the volume, issue and page numbers.

Link to publication

\footnotetext{
General rights rights.

- You may freely distribute the URL identifying the publication in the public portal. please follow below link for the End User Agreement:

www.umlib.nl/taverne-license

Take down policy

If you believe that this document breaches copyright please contact us at:

repository@maastrichtuniversity.nl

providing details and we will investigate your claim.
}

Copyright and moral rights for the publications made accessible in the public portal are retained by the authors and/or other copyright owners and it is a condition of accessing publications that users recognise and abide by the legal requirements associated with these

- Users may download and print one copy of any publication from the public portal for the purpose of private study or research.

- You may not further distribute the material or use it for any profit-making activity or commercial gain

If the publication is distributed under the terms of Article $25 \mathrm{fa}$ of the Dutch Copyright Act, indicated by the "Taverne" license above, 


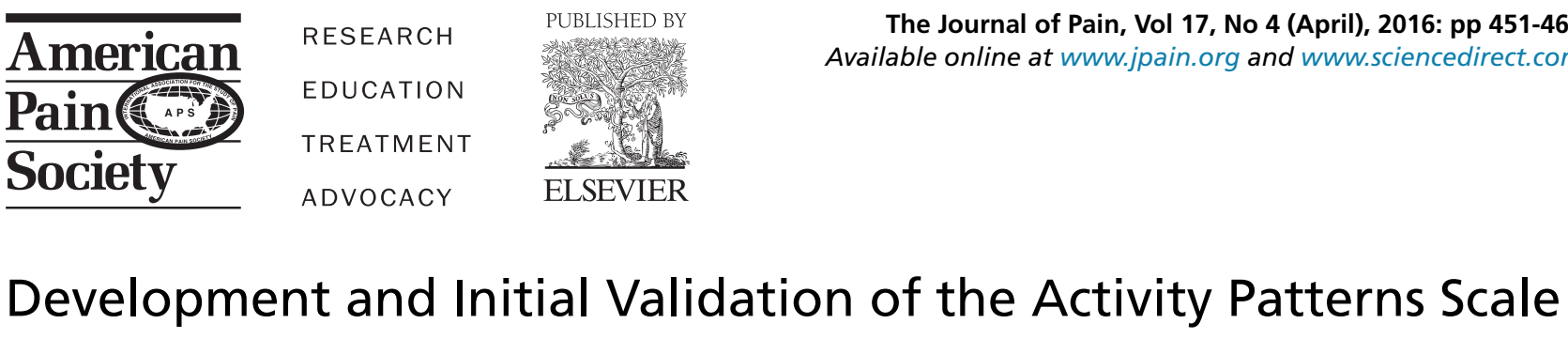 in Patients With Chronic Pain
}

\author{
Rosa Esteve, ${ }^{*}$ Carmen Ramírez-Maestre, ${ }^{*}$ Madelon L. Peters, ${ }^{\dagger}$ Elena R. Serrano-Ibáñez, * \\ Gema T. Ruíz-Párraga, * and Alicia E. López-Martínez* \\ *Universidad de Málaga, Andalucía Tech, Facultad de Psicología, Málaga, Spain. \\ ${ }^{\dagger}$ Maastricht University, Department of Psychology and Neuroscience, Clinical Psychological Science, Behavioural \\ Medicine, Maastricht, The Netherlands.
}

\begin{abstract}
Several self-report measures were used to identify 6 activity patterns in chronic pain patients: pain avoidance, activity avoidance, task-contingent persistence, excessive persistence, pain-contingent persistence, and pacing. Instruments for assessing pacing should include 3 pacing behaviors (breaking tasks into smaller tasks, taking frequent short rests, slowing down), each of which relate to a single goal (increasing activity levels, conserving energy for valued activities, and reducing pain). This article presents the Activity Patterns Scale (APS), which assesses these 6 activity patterns. Study 1 included 291 participants with chronic pain, and tested 3 structures using confirmatory factor analyses. The structure with the best fit had $\mathbf{8}$ factors corresponding to the hypothesized scales. High correlations in the expected direction were found between the APS subscales and the "Patterns of Activity Measure-Pain." Study 2 included 111 patients with chronic pain, and aimed at examining the association between the APS subscales and adjustment to pain. It was found that that activity avoidance was associated with daily functioning and impairment. Negative affect was positively associated with activity avoidance and excessive persistence, and negatively associated with task-contingent persistence, which was also positively associated with positive affect. This study showed that the APS is a valid and reliable instrument for clinical practice and research.

Perspective: This article presents a valid and reliable instrument to assess activity patterns in patients with chronic pain. The findings suggest that avoidance, persistence, and pacing are multidimensional constructs. Distinguishing between these dimensions sheds light on previous contradictory results and has direct clinical implications regarding recommending the most advisable activity patterns.
\end{abstract}

(c) 2016 by the American Pain Society

Key words: Activity patterns, avoidance, persistence, pacing, chronic pain.

$\mathrm{T}$ he well-being of individuals with chronic pain is partly associated with the different ways in which they engage in daily activities. Three activity patterns have been distinguished: avoidance, persistence, and pacing behavior. On theoretical grounds, avoidance and persistence are both expected to be associated with

\footnotetext{
Received October 15, 2015; Revised December 5, 2015; Accepted December 5, 2015.

Supported by grants from the Spanish Ministry of Science and Innovation (PSI2013-42512- P), and the Regional Government of Andalusia (HUM566)

The authors have no conflicts of interest to declare.

Address reprint requests to Rosa Esteve, PhD, Departamento de Personalidad, Evaluación y Tratamiento Psicológico, Facultad de Psicología, Universidad de Málaga, 29071- Málaga, Spain. E-mail: zarazaga@uma.es $1526-5900 / \$ 36.00$

(C) 2016 by the American Pain Society

http://dx.doi.org/10.1016/j.jpain.2015.12.009
}

functional disability. ${ }^{14,39}$ In contrast, pacing was traditionally thought to have positive effects and has been used as a treatment strategy ${ }^{29}$; nevertheless, empirical research has revealed a more complex picture. A meta-analysis ${ }^{4}$ that investigated the relationship between different approaches to activity and functioning in chronic pain patients consistently found that activity avoidance was linked to worse physical and psychological functioning and increased pain. The relationship between persistence and functioning appeared to depend on the measure used: instruments that assessed overactivity were linked to poorer outcomes, whereas instruments that assessed persisting with activity despite pain were associated with positive outcomes. Finally, pacing was not only linked to better psychological functioning but, contrary to expectations, also to higher levels of pain and disability. 
In summary, the results of research on the relationship between activity patterns and well-being are far from clear. Andrews et al ${ }^{4}$ suggested that because of the variance seen between effect sizes in their meta-analysis, there may be a need to develop new measures of activity patterns or to refine existing ones. Similarly, Kindermans et $\mathrm{al}^{22}$ suggested that these ambiguous results could be due to dimensions underlying these 3 widely accepted general patterns; using exploratory factor analyses of various activity patterns in self-report measures, the authors identified the following activity patterns in patients with chronic pain: pain avoidance (avoidance behavior in the presence or anticipation of changes in pain); activity avoidance (avoidance refers to the patients' condition of being in pain rather than the fluctuating pain experience); task-contingent persistence (behavioral persistence in finishing tasks or activities despite pain); excessive persistence (doing too much, not respecting one's physical limits, and experiencing the rebound effects of heightened activity levels); paincontingent persistence (the level of experienced pain as the determinant of the behavior performed with activity fluctuating over time as a result); and pacing (dividing daily activities into smaller tasks). Although Kindermans et $\mathrm{al}^{22}$ found that pacing was a unidimensional construct, Nielson et $\mathrm{al}^{27,28}$ considered pacing to be multidimensional and suggested that existing measures do not include some key pacing subdomains. The authors proposed that future measures should be developed that address a specific pacing behavior with a single goal. They identified the following pacing behaviors: breaking tasks into smaller, manageable tasks; taking frequent short rests; and slowing down. They proposed the following as the main aims of pacing: increasing activity levels; energy conservation for valued activities; and pain reduction. No existing pacing measure assesses these aims and thus a new pacing measure is needed that links each pacing behavior to each of these 3 objectives.

Study 1 constructed a self-report instrument to assess the activity patterns identified by Kindermans et $\mathrm{al}^{22}$ : The Activity Patterns Scale (APS). The 3 items with the highest factor loading in the study by Kindermans et $\mathrm{al}^{22}$ were included. Following the proposal by Nielson et $\mathrm{al}^{27,28}$ the 3 pacing subscales were constructed such that each specific behavior was related to 1 of the aforementioned goals. The internal structure of the APS was examined by confirmatory factor analysis. Study 1 also explored the association between each subscale and the subscales of a consolidated measure of activity patterns (ie, the Patterns of Activity Measure-Pain [POAM-P]) ${ }^{9}$ subscales. Study 2 analyzed the relationship between the APS subscales and pain intensity, daily functioning, impairment, and positive and negative affect.

\section{Methods}

\section{Procedure}

These studies form part of a larger research project and were approved by the University of Málaga Ethics
Committee. In study 1, the Spanish associations of patients with fibromyalgia and rheumatic diseases were contacted via e-mail and their collaboration was requested in disseminating an online protocol among their members. The participants accessed the online protocol using the link provided by their respective associations. Participants were informed that their answers would remain confidential. The data were collected between October 2014 and January 2015.

In study 2, participants were recruited through 2 local associations of patients with fibromyalgia, an association of patients with rheumatic diseases, and through doctors working at the Pain Unit of the Hospital Costa del Sol. The data were collected between January 2015 and May 2015. Individuals were considered eligible for inclusion if they met the following criteria: At the moment of participation in the study they were experiencing pain and had been experiencing pain for at least the past 6 months; they were between 18 and 65 years old; they were not being treated for a malignancy, terminal illness, or psychiatric disorder; they were able to understand the Spanish language (spoken and written); and they were able to understand the instructions and the questionnaires. Patients were informed of the study aims, confidentiality was assured, and informed consent was obtained. Each participant had a semistructured interview with a trained psychologist to obtain demographic, social, and medical history data, and then they completed the questionnaires described in the Measures section.

\section{Statistical Analyses}

The internal structure of the APS was examined using confirmatory factor analysis via structural equation modeling using the Lisrel 8.30 software package. ${ }^{20}$ Analyses were performed on the polychoric correlation matrix of the APS items using the maximum likelihood and robust estimation methods. The following goodness-offit indexes were used: Satorra-Bentler $\chi^{2}{ }^{6}$ the Comparative Fit Index (CFI), ${ }^{7}$ the Non-Normed Fit Index (NNFI), ${ }^{8}$ the root mean-square error of approximation (RMSEA), and the Akaike Information Criterion ${ }^{1}$ (AIC). The Satorra-Bentler $\chi^{2}$ is a $\chi^{2}$ fit index that corrects the statistic under distributional violations; to reduce the sensitivity of $\chi^{2}$ to sample size, the index is divided by the degrees of freedom. ${ }^{6}$ Ratios of 2 or less are indicative of an acceptable fit of the model. ${ }^{23}$ The CFI and NNFI measure the proportional improvement in fit by comparing a hypothesized model with the null model as the baseline model. The CFI and NNFI range from 0 (absolute lack of fit) to 1 (perfect fit) and fit is considered to be good when the values are $>.90 .^{16}$ The RMSEA is an absolute misfit index; the closer to 0 , the better the fit. Values $<.08$ indicate an adequate fit and values $<.06$ indicate a good fit. ${ }^{16,17}$ Finally, the AIC index ${ }^{1}$ allows alternative models to be compared by taking into account parsimony (in the sense of the number of parameters) as well as fit. This index can be used regardless of whether or not the models can be ordered in a nested sequence. In this approach, the models are ranked according to their AIC values and the model with the smallest value is chosen. 
Cronbach $\alpha$ and corrected item-factor correlations were calculated to assess the internal consistency of the APS. The criterion validity of the APS was assessed by examining the association between each subscale and the subscales of the POAM-P. Study 2 used correlation analyses to examine the relationship between the APS subscales and daily functioning, impairment, and positive and negative affect. Correlations were interpreted following the guidelines proposed by Cohen, ${ }^{10}$ wherein low correlations range from .10 to .29 , moderate correlations range from .30 to .49 , and high correlations range from .50 to 1 .

\section{Study 1}

The aim of study 1 was to examine the internal structure of the APS. Eight internally consistent subscales were postulated corresponding to 5 of the 6 activity patterns identified by Kindermans et $\mathrm{al}^{22}$ (pain avoidance, activity avoidance, task-contingent persistence, excessive persistence, and pain-contingent persistence) and 3 pacing subscales each of which referred to 1 of the goals proposed by Nielson et $\mathrm{al}^{27,28}$ (increasing activity levels, conserving energy for valued activities, and reducing pain). It was predicted that the pain avoidance and activity avoidance APS subscales would be positively correlated with the POAM-P avoidance subscale; that the APS task-contingent persistence, excessive persistence, and pain-contingent persistence subscales would be positively correlated with the POAM-P overdoing subscale; and that the 3 APS pacing subscales would be positively correlated with the POAM-P pacing subscale.

\section{Participants}

The sample was comprised of 291 chronic pain patients ( 262 women and 29 men). The average age was 52 years (SD 9.86). At the time of the study, $76.6 \%$ were married or cohabiting. Regarding their work status, $32.6 \%$ were active workers, $26.8 \%$ were retired, and $21.3 \%$ were unemployed. A total of $40.5 \%$ had completed high school education and $21.3 \%$ had completed primary education. The median pain duration was 17 years (SD 10.93). In total, 229 patients had fibromyalgia and 62 patients had other rheumatic diseases.

This sample met the recommended 10:1 ratio of the number of subjects to the number of test items required by factor analysis. ${ }^{23}$

\section{Measures}

\section{The POAM-P ${ }^{9}$}

The POAM-P measures 3 activity patterns in patients with chronic pain: avoidance, overdoing, and pacing. It is a 30 -item self-report questionnaire with 3 subscales each consisting of 10 statements. Participants are asked to indicate to what extent the statement applies to them on a 5-point scale ranging from 0 (not at all) to 4 (always). The forward-backward translation method was used to obtain the final Spanish version. First, the original version of the POAM-P was translated into Spanish by 2 native Spanish clinical psychologists familiar with the terminology of the area covered by the instrument. Thus, 2 Spanish versions were obtained, which were compared for inconsistencies. These inconsistencies were taken into account, and a new draft of the instrument was produced on the basis of the corrections. This Spanish version was then translated into English by a professional native translator familiar with psychological terminology. The inconsistencies were then corrected in the final Spanish version. Initial reliability checks of the Spanish version of the POAM-P were satisfactory (avoidance subscale, $\alpha=.88$; overdoing subscale, $\alpha=.85$; pacing subscale, $\alpha=.91$ ). The intercorrelations between the subscales were as follows: avoidance and overdoing, $r=-.25$ $(P=.01)$; avoidance and pacing, $r=.56(P=.01)$; and overdoing and pacing, $r=-.22(P=.01)$.

\section{The APS}

A self-report instrument was constructed to assess the activity patterns identified by Kindermans et $\mathrm{al}^{22}$ using factor analysis of the following instruments, which evaluate activity patterns: 1) the POAM-P, previously described; 2) the Pain and Activity Relations Questionnaire, ${ }^{26}$ which is a 21 -item self-report instrument that measures 3 activity patterns (avoidance, confronting, and pacing). A 6-point scale is used to rate each statement ( $0=$ never; $5=$ always); 3 ) The Behavioral Responses to Illness Questionnaire, ${ }^{36}$ which is a 21 -item self-report instrument composed of 4 subscales (Kindermans et $\mathrm{al}^{22}$ only included 2 subscales: "all-or-nothing behavior" and "limiting behavior", corresponding to persistence and avoidance behaviors, respectively). Items are answered on a 5-point scale ( $1=$ not at all, $0=$ every day), referring to the frequency of the stated behavior by the participant; and 4) the Chronic Pain Coping Inventory, ${ }^{19,26}$ which is a self-report instrument comprised of 9 subscales referring to concrete strategies to cope with pain. Kindermans et $\mathrm{al}^{22}$ only included the subscales "task persistence" (6 items) and "pacing" (6 items). The items are answered on an 8-point scale in which the participants have to indicate on how many days they performed a particular coping strategy during the past week (range $=0-7$ days).

The 3 items with the highest factor loading in each activity pattern dimension found by Kindermans et $\mathrm{al}^{22}$ were included in the instrument. Table 1 shows the questionnaires from which the Kindermans et $\mathrm{al}^{22}$ items were selected. In addition, the proposals of Nielson et $\mathrm{al}^{27}$ were followed to construct 3 pacing scales according to the goal of each specific behavior. The pacing items were developed in the following way: 1) the items were developed on a rational basis according to the proposals of Nielson et $\mathrm{al}^{27,28}$; 2) 4 independent judges, who were experts on psychological aspects of chronic pain, rated the adequacy of the items according to the definition of the constructs; and 3) a pilot study was conducted in which the items were presented orally to 10 patients with chronic pain with the aim of detecting problems in understanding. 
Table 1. Means, SDs, and Corrected Item-Factor Correlations of the Items of the APS

\begin{tabular}{|c|c|c|c|c|}
\hline FACTORS/ITEMS & MEAN & $S D$ & $\begin{array}{c}\text { CORRECTED } \\
\text { ITEM-FACTOR } \\
\text { CORRELATIONS }\end{array}$ & $\alpha$ \\
\hline Factor I: Pain avoidance & & & & .56 \\
\hline 1. I stop what I am doing when my pain starts to get worse (POAM-P) & 2.44 & 1.01 & .23 & \\
\hline 11. If I know that something will make my pain worse I don't do it anymore (POAM-P) & 2.00 & 1.24 & .45 & \\
\hline 16. I avoid activities that cause pain (PARQ) & 2.25 & 1.23 & .43 & \\
\hline Factor II: Activity avoidance & & & & .60 \\
\hline 6. I have not been able to carry on with my usual level of activity (BRIQ) & 2.49 & 1.25 & .36 & \\
\hline 8. Because of my pain most days I spend more time resting than doing activities (POAM-P) & 2.14 & 1.24 & .38 & \\
\hline 13. I have to put parts of my life on hold (BRIQ) & 2.73 & 1.10 & .49 & \\
\hline Factor III: Task-contingent persistence & & & & .81 \\
\hline 2. Kept on doing what I was doing (CPCI) & 2.03 & 1.16 & .61 & \\
\hline 10. I just kept going $(\mathrm{CPCI})$ & 1.83 & 1.31 & .70 & \\
\hline 21. Once I start an activity I keep going until it is done (POAM-P) & 1.87 & 1.28 & 69 & \\
\hline Factor IV: Excessive persistence & & & & .69 \\
\hline 4. I have tried to do too much and felt even worse as a result (BRIQ) & 2.28 & 1.40 & .57 & \\
\hline 7. I find myself rushing to get everything done before I crash (BRIQ) & 1.44 & 1.36 & .50 & \\
\hline 15. I have overdone things, then needed to rest up for a while (BRIQ) & 2.34 & 1.23 & .51 & \\
\hline Factor V: Pain-contingent persistence & & & & .84 \\
\hline 18. When my pain decreases I try to be as active as possible (PARQ) & 2.96 & 1.13 & .66 & \\
\hline 20. I do extra on days when my pain is less (POAM-P) & 2.66 & 1.23 & .73 & \\
\hline 22. I make the most of my good pain days by doing more things (POAM-P) & 2.94 & 1.15 & .72 & \\
\hline Factor VI: Pacing for the purpose of increasing activity level & & & & .69 \\
\hline 3. I usually take several breaks and so I can do a lot more things & 2.35 & 1.17 & .42 & \\
\hline 17. I do things more slowly so that I can do a lot more things & 1.91 & 1.21 & .52 & \\
\hline 19. I split activities into smaller parts and so I can do a lot more things & 1.98 & 1.21 & .60 & \\
\hline Factor VII: Pacing for the purpose of conserving energy for valued activities & & & & .76 \\
\hline 5. I split activities into smaller steps so I can save energy to do other things that matter to me & 2.10 & 1.27 & .53 & \\
\hline 14. I usually take several breaks and so I can save energy to do other things that matter to me & 2.20 & 1.21 & .63 & \\
\hline 23. I do things more slowly and so I can save energy to do other things that matter to me & 2.04 & 1.23 & .62 & \\
\hline Factor VIII: Pacing for the purpose of pain reduction & & & & .72 \\
\hline 9. I do things slowly so that it hurts less & 2.22 & 1.27 & .53 & \\
\hline 12. I split activities into smaller steps so that it hurts less & 2.04 & 1.23 & .58 & \\
\hline 24. I usually take several breaks so that it hurts less & 2.26 & 1.23 & .52 & \\
\hline
\end{tabular}

Abbreviations: PARQ, Pain and Activity Relations Questionnaire; BRIQ, Behavioral Responses to Illness Questionnaire; CPCI, Chronic Pain Coping Inventory. NOTE. The numbers that precede each item refer to the item numeration on the scale.

In summary, the instrument consists of 24 items grouped into 8 three-item subscales: pain avoidance, activity avoidance, task-contingent persistence, excessive persistence, pain-contingent persistence, pacing to increase activity levels, pacing to conserve energy for valued activities, and pacing to reduce pain. Participants are asked to indicate to what extent the statement applies to them on a 5-point scale ranging from 0 (not at all) to 4 (always). The items that comprised the new instrument underwent a forward-backward translation method similar to the one previously described.

\section{Results}

\section{Preliminary Analyses}

Preliminary correlation analyses and mean comparisons were performed to examine the relationship between the APS subscales and several demographic and clinical variables. No significant associations or differences were found in relation to age, sex, education, pain duration, or diagnosis. Analysis of variance was used to compare groups according to work status, and differences were found between groups in pacing to reduce pain $\left(F_{4,286}=4.783, P<.001\right)$, and pacing to increase activity levels $\left(F_{4,286}=3.137, P=.015\right)$. Post hoc tests indicated that retired patients had significantly higher scores than patients in active work on both subscales.

\section{Factorial Structure, Internal Consistency, and Corrected Item-Factor Correlations}

Confirmatory factor analysis was performed to examine the internal structure of the APS. Three alternative factor structures were tested:

1) Three-Factor Structure

The items were specified to the following factors: avoidance (items $1,6,8,11,13,16$ ), persistence (items $2,4,7,10,15,18,20,21,22$ ), and pacing (items $3,5,9,12,14,17,19,23,24)$.

2) Six-Factor Structure

The items were specified to the factors identified by Kindermans et al ${ }^{22}$ : pain avoidance (items 1, 11, 16), activity avoidance (items $6,8,13$ ), task- contingent persistence (items $2,10,21$ ), excessive persistence (items 4, 7, 15), pain-contingent persistence 
(items 18, 20, 22), and pacing (items 3, 5, 9, 12, 14, 17, 19, 23, 24).

3) Eight-Factor Structure

The items were specified to the following factors: pain avoidance (items 1, 11, 16), activity avoidance (items 6, 8, 13), task-contingent persistence (items 2,10,21), excessive persistence (items 4, 7, 15), pain-contingent persistence (items 18, 20,22 ), pacing to increase activity levels (items 3 , $17,19)$, pacing to conserve energy for valued activities (items $5,14,23$ ), and pacing to reduce pain (items 9, 12, 24).

Table 1 shows the corrected item factor correlations and the internal consistency, which ranged from $\alpha=.56$ for the pain avoidance subscale to $\alpha=.84$ for the paincontingent persistence subscale.

Table 2 shows all the goodness-of-fit indexes of the 3 models tested. As can be seen, the 3 related factors model failed to meet the recommended cutoff criteria. The fit of the 6 and the 8 related factors models were acceptable, although the fit of the 8 related factors model was slightly better. The AIC index showed that the 8 related factors model had the smallest value and thus the best fit. As shown in Figure 1, all of the factor loadings of this model were significant $(P<.05)$.

\section{Intercorrelations Between the APS Subscales}

The pain avoidance subscale was positively and moderately correlated with the activity avoidance subscale, which suggests that although both aspects of avoidance are related, they should be distinguished from each other (Table 3). It should also be noted that the pain avoidance subscale had positive moderate to high (.38-.51) correlations with the 3 pacing subscales. Although the pain avoidance and activity avoidance subscales were not correlated with the excessive persistence and pain-contingent persistence subscales, they had low negative correlations with the task-contingent persistence subscale. The activity avoidance subscale had positive low to moderate correlations (.19-.32) with the 3 pacing subscales, although the magnitude of these associations was lower than those of the pain avoidance and pacing subscales. The 3 persistence subscales were moderately correlated with each other, but were not correlated or had low correlations with the pacing subscales. Finally, it should be noted that the 3 pacing subscales were highly correlated.

Table 2. Confirmatory Factor Analysis of the APS: Goodness-of-Fit Indexes

\begin{tabular}{lccccc}
\begin{tabular}{l} 
Alternative Factor \\
\multicolumn{1}{c}{ Structures }
\end{tabular} & $\chi^{2} / d f^{*}$ & NNFI & CFI & RMSEA & \multicolumn{1}{c}{ AIC } \\
\hline Three factors & 3.85 & .88 & .89 & .099 & $1,061.39$ \\
Six related factors & 2.27 & .95 & .96 & .066 & 663.97 \\
Eight related factors & 2.19 & .95 & .96 & .064 & 594.59 \\
\hline
\end{tabular}

Abbreviation: df, degrees of freedom.

* Satorra-Bentler $\chi^{2}$ divided by degrees of freedom.

\section{Criterion Validity}

The association between the 8 APS subscales and the POAM-P subscales was examined. Because the APS contains some items in common with the POAM-P, the items in common were eliminated from the POAM-P and the correlations between the APS and the POAM-P were calculated. As shown in Table 4, high correlations in the expected direction were found between the APS and POAM-P subscales. Interestingly, although the APS pacing subscales had the highest correlation with the POAM-P pacing subscale, they also had moderate to

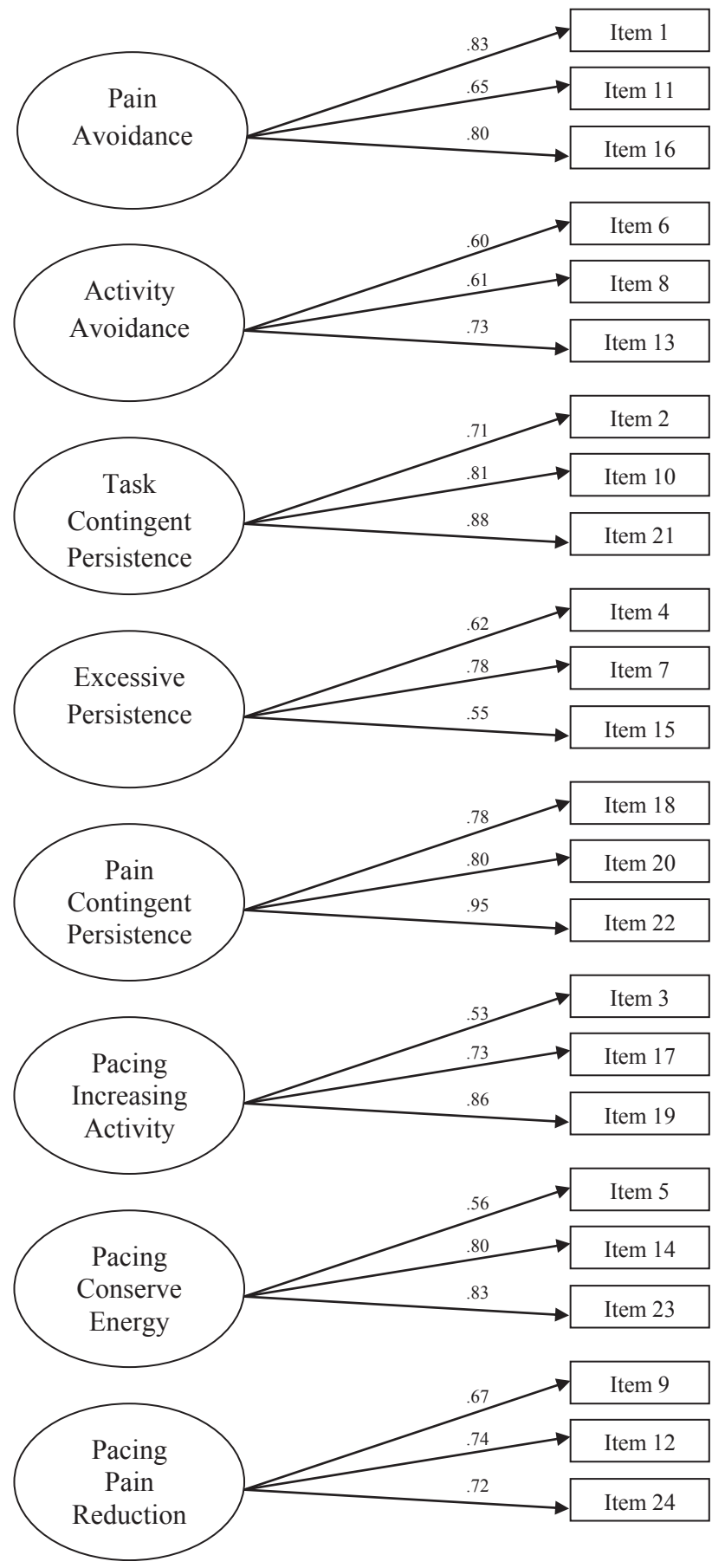

Figure 1. Confirmatory factor analysis of the APS; 8 related factors solution. Decimal numbers positioned near arrows represent factor loadings on each subscale. 
Table 3. Intercorrelations Between the APS Subscales

\begin{tabular}{|c|c|c|c|c|c|c|c|c|}
\hline SUBSCALE & $\begin{array}{c}\text { PAIN } \\
\text { AvoIDANCE }\end{array}$ & $\begin{array}{c}\text { ACTIVITY } \\
\text { AVOIDANCE }\end{array}$ & $\begin{array}{c}\text { TASK-CONTINGENT } \\
\text { PERSISTENCE }\end{array}$ & $\begin{array}{c}\text { EXCESSIVE } \\
\text { PERSISTENCE }\end{array}$ & $\begin{array}{c}\text { Pain-Contingent } \\
\text { PeRsistence }\end{array}$ & $\begin{array}{c}\text { PACING FoR } \\
\text { INCREASING } \\
\text { ACTIVITY LEVEL }\end{array}$ & $\begin{array}{c}\text { PACING For } \\
\text { CONSERVING ENERGY } \\
\text { FOR VALUED ACTIVITIES }\end{array}$ & $\begin{array}{c}\text { PACING } \\
\text { FOR PAIN } \\
\text { REDUCTION }\end{array}$ \\
\hline Pain avoidance & 1 & $.33^{*}$ & $-.27^{\star}$ & -.07 & -.012 & $.38 *$ & $.46^{*}$ & $.51 *$ \\
\hline Activity avoidance & & 1 & $-.23^{*}$ & .08 & .09 & $.19 *$ & $.25^{*}$ & $.32 *$ \\
\hline $\begin{array}{l}\text { Task-contingent } \\
\text { persistence }\end{array}$ & & & 1 & $.43^{*}$ & $.35^{\star}$ & -.08 & $-.15^{*}$ & $-.20^{\star}$ \\
\hline Excessive persistence & & & & 1 & $.39 *$ & .10 & .05 & -.09 \\
\hline $\begin{array}{l}\text { Pain-contingent } \\
\text { persistence }\end{array}$ & & & & & 1 & $.20^{\star}$ & $.18^{*}$ & .07 \\
\hline $\begin{array}{l}\text { Pacing for increasing } \\
\text { activity level }\end{array}$ & & & & & & 1 & $.75^{\star}$ & $.75^{\star}$ \\
\hline $\begin{array}{l}\text { Pacing for conserving } \\
\text { energy for valued } \\
\text { activities }\end{array}$ & & & & & & & 1 & $.75^{\star}$ \\
\hline $\begin{array}{l}\text { Pacing for pain } \\
\text { reduction }\end{array}$ & & & & & & & & 1 \\
\hline
\end{tabular}

$* P<.01$

high correlations with the POAM-P avoidance subscale. Similarly, the APS pain avoidance subscale had a moderate correlation with the POAM-P pacing subscale. The 3 APS persistence subscales had high positive correlations with the POAM-P overdoing subscales. It is also worth noting that whereas the APS excessive persistence subscale and APS pain-contingent persistence subscale were not correlated with the POAM-P avoidance subscale, the APS task-contingent persistence subscale had a moderate negative correlation with the POAM-P avoidance subscale.

\section{Study 2}

Study 2 examined the association between the APS subscales and pain intensity, daily functioning, impairment, and positive and negative affect. Avoidance and persistence were expected to be positively correlated with pain intensity, functional impairment, and negative affect, and negatively with daily functioning and positive affect. Pacing was expected to be negatively correlated with pain intensity, functional impairment, and negative affect, and positively with daily functioning and positive affect.

Table 4. Correlations Between the APS Subscales and the POAM-P

\begin{tabular}{lccc}
\hline \multicolumn{1}{c}{ APS SUBSCALES } & POAM-P & POAM-P & POAM-P \\
& AVOIDANCE & OVERDOING & PACING \\
\hline Pain avoidance & $.69^{*}$ & $-.31^{*}$ & $.47^{*}$ \\
Activity avoidance & $.45^{*}$ & -.02 & $.21^{*}$ \\
Task-contingent persistence & $-.31^{*}$ & $.68^{*}$ & $-.27^{*}$ \\
Excessive persistence & -.08 & $.55^{*}$ & -.08 \\
Pain-contingent persistence & -.01 & $.48^{*}$ & .05 \\
Pacing for increasing activity level & $.40^{*}$ & -.06 & $.75^{*}$ \\
Pacing for conserving energy for & $.53^{*}$ & -.15 & $.81^{*}$ \\
$\quad$ valued activities & & & $.80^{*}$ \\
Pacing for pain reduction & $.60^{*}$ & $-.20^{*}$ & \\
\hline$* P<.01$. & & &
\end{tabular}

\section{Participants}

The sample was comprised of 111 chronic pain patients ( 81 women and 30 men). The average age was 53 years (SD 8.54). At the time of the study, $79.3 \%$ were married or cohabiting. Regarding their work status, 31.5\% were active workers, $31.5 \%$ were retired, $20.7 \%$ were unemployed, and $15.3 \%$ were homemakers.

A total of $29.7 \%$ had completed high school education and $47.7 \%$ had completed primary education. The median pain duration was 14.69 years (SD 11.59). The participants had musculoskeletal pain of different etiologies: fibromyalgia (36.04\%), discogenic pain (23.42\%), arthritis $(15.32 \%)$, osteoarthritis $(11.71 \%)$, osteoporosis $(4.5 \%)$, and other $(9.01 \%)$.

\section{Measures}

In addition to the APS described in study 1, the measures in the following sections were applied.

\section{Positive and Negative Affect Schedule ${ }^{40}$}

The Spanish version of this scale was used ${ }^{33,34}$ This instrument is one of the most reliable, valid, and efficient means for measuring positive and negative affect. It is comprised of two 10-item scales that are internally consistent and have demonstrated appropriate stability over a 2-month time period. The Spanish Positive and Negative Affect Schedule also has excellent construct and criterion validity.

\section{Pain intensity}

Patients were asked to rate their mildest, average, and worst pain during the past 2 weeks, as well as their current pain, on a scale ranging from 0 to 10 , with a " 0 " indicating "no pain" and "10" indicating pain as "intense as you could imagine." A composite pain intensity score was calculated for each subject by calculating the average of the mildest, average, worst, and current pain. $^{18}$ 


\section{Impairment and Functioning Inventory ${ }^{30,31}$}

The Impairment and Functioning Inventory (IFI) consists of 30 items each referring to a specific activity associated with 1 of the following areas: household (eg, make the beds), autonomous behavior (eg, dress by yourself), leisure (eg, go to a bar or cafe), and social relationships (eg, visit friends). First, patients are asked if they performed an activity during the previous week (or during the previous month for certain activities). If they performed the activity, they are asked how often they performed it, answering on a 5-point scale $(0=$ never, 1 = between 1 and 2 times, 2 = between 3 and 6 times, 3 = between 6 and 9 times, $4=\geq 10$ times). If they did not perform the activity, they are asked if they practiced this activity before the onset of their chronic pain. The instrument provides an index of daily functioning, and an index of activity impairment. The 'daily functioning index' is calculated by adding the frequencies at which every activity is performed. The 'activity impairment index' is calculated by adding the total number of activities that the patients have given up since pain began. This approach differentiates between present functioning and impairment and is useful in assessing patients with a long history of pain, for whom the degree of deterioration is at least as informative as the current level of functioning. ${ }^{30,31}$ The global scales are both highly reliable.

\section{Results}

\section{Internal Consistency}

The subscales showed adequate internal consistency and the values obtained were higher than in study 1 :

Table 5. Correlations Between the APS Subscales and Pain Intensity, Positive Affect, Negative Affect, Daily Functioning, and Activity Impairment

\begin{tabular}{|c|c|c|c|c|c|}
\hline APS SUBSCALES & $\begin{array}{c}\text { PAIN } \\
\text { INTENSITY }\end{array}$ & $\begin{array}{c}\text { PANAS } \\
\text { POSITIVE } \\
\text { AFFECT }\end{array}$ & $\begin{array}{c}\text { PANAS } \\
\text { NEGATIVE } \\
\text { AFFECT }\end{array}$ & $\begin{array}{c}\text { DAILY } \\
\text { FUNCTIONING }\end{array}$ & $\begin{array}{c}\text { ACTIVITY } \\
\text { IMPAIRMENT }\end{array}$ \\
\hline Pain avoidance & .14 & .09 & -.02 & -.09 & $.25^{*}$ \\
\hline Activity avoidance & .24 & $-.29 * *$ & $.40 * *$ & $-.50 * \star$ & $.59 * *$ \\
\hline $\begin{array}{c}\text { Task-contingent } \\
\text { persistence }\end{array}$ & -.17 & $.52 * \star$ & $-.38 * \star$ & $.33 * *$ & $-.30 * *$ \\
\hline $\begin{array}{l}\text { Excessive } \\
\text { persistence }\end{array}$ & .08 & .02 & $.31 * *$ & $.22 *$ & -.10 \\
\hline $\begin{array}{l}\text { Pain-contingent } \\
\text { persistence }\end{array}$ & -.11 & .18 & .10 & $.39 * *$ & $-.23 *$ \\
\hline $\begin{array}{l}\text { Pacing for } \\
\text { increasing } \\
\text { activity level }\end{array}$ & .02 & $.24^{\star}$ & -.18 & $.40 * *$ & -.12 \\
\hline $\begin{array}{l}\text { Pacing for } \\
\text { conserving } \\
\text { energy for } \\
\text { valued activities }\end{array}$ & .05 & $.28 * *$ & $-.21^{\star}$ & $30 * *$ & -.18 \\
\hline $\begin{array}{l}\text { Pacing for pain } \\
\text { reduction }\end{array}$ & .06 & -.07 & .00 & -.01 & -.09 \\
\hline
\end{tabular}

Abbreviation: PANAS, Positive and Negative Affect Schedule.

$* P<.05$.

$* * P<01$ pain avoidance $(\alpha=.80)$, activity avoidance $(\alpha=.73)$, task-contingent persistence $(\alpha=.83)$, excessive persistence $(\alpha=.73)$, pain-contingent persistence $(\alpha=.82)$, pacing to increase activity ( $\alpha=.76)$, pacing to conserve energy $(\alpha=.83)$, and pacing to reduce pain $(\alpha=.76)$.

\section{Criterion Validity}

Correlations were examined between the 8 APS subscales, pain, positive and negative affect, daily functioning, and impairment. As shown in Table 5, no significant correlations were found between pain intensity and any of the APS subscales. The activity avoidance subscale had significant correlations with the rest of the criterion variables: a high and positive correlation with activity impairment and a high and negative correlation with daily functioning; and a moderate positive correlation with negative affect and a moderate negative correlation with positive affect. Pain avoidance had a low positive correlation with activity impairment.

The task-contingent persistence subscale had moderate negative correlations with negative affect and activity impairment, a positive moderate correlation with daily functioning, and a high positive correlation with positive affect. In contrast, excessive persistence had a positive moderate correlation with negative affect and a positive low correlation with daily functioning. Pain-contingent persistence had a moderate positive correlation with daily functioning and a low negative correlation with activity impairment.

Pacing to increase activity levels had a positive moderate correlation with daily functioning and a positive low correlation with positive affect. Pacing to conserve energy for valued activities had a moderate positive correlation with daily functioning, a low positive correlation with positive affect, and a low negative correlation with negative affect. Pacing to reduce pain was not correlated with any of the criteria variables.

\section{Conclusions}

The aims of this research were 1) to develop a selfreport instrument to assess the activity patterns identified by Kindermans et al. ${ }^{22}$ The instrument also included 3 pacing subscales in which each specific behavior was related to a concrete goal; 2) to examine its internal structure; and 3) to assess its criterion validity by examining its association with the POAM-P and with pain intensity, daily functioning, impairment, and positive and negative affect.

Confirmatory factor analysis of the APS supported the validity of a 24 -item version with 8 subscales corresponding to 8 related factors. These results showed that avoidance, persistence, and pacing are best conceived as multidimensional constructs, and that the dimensions underlying these constructs should be distinguished from each other. This conclusion is also supported by the finding of differential patterns of relationships between the APS subscales and between the APS subscales and several criteria. 
As consistently found in previous research, ${ }^{4}$ and postulated by the fear avoidance model, ${ }^{39}$ the results of the present study showed that activity avoidance was associated with poorer physical and psychological functioning. In contrast, pain avoidance had a small positive correlation with activity impairment and no correlation with the remaining criteria. It should be borne in mind that activity avoidance is related to the general condition of the patient rather than to pain itself, whereas pain avoidance reflects avoidance behavior specifically aimed at minimizing or preventing the pain experience. Thus, the results highlight the importance of distinguishing between these 2 types of avoidance patterns. Kindermans et $\mathrm{al}^{22}$ found similar patterns of relationships between both forms of avoidance and the criteria; nevertheless, when controlling for the other activity patterns and pain intensity, activity avoidance alone remained a statistically significant predictor of disability. To fully understand the results of the present study, it should be emphasized that daily functioning was operationalized as the frequency at which patients performed activities related to the household, autonomous behavior, leisure, and social relationships; activity impairment was operationalized as the number of activities that patients have given up since they began experiencing their pain problem. The instrument used (IFI) does not measure pain interference, which could have some conceptual overlap with measures of activity avoidance. ${ }^{5,38}$ The IFI conceptualizes disability according to the definition given by the International Classification of Functioning, Disability, and Health. ${ }^{42}$

To our knowledge, this is the first study in which, following the proposal of Nielson et al, ${ }^{28} 3$ different patterns of pacing have been distinguished according to their goal: increasing activity levels, conserving energy for valued activities, and reducing pain. It is noteworthy that although the correlation between the APS pain avoidance subscale and the APS pacing to reduce pain subscale was high, the correlation was even higher than that between the 2 APS avoidance subscales. A possible explanation for this result is that both patterns of activity are directed to the same goal-reducing pain intensity-and could be considered functionally equivalent behaviors. These results are in line with those of several studies that have shown that pacing measures are strongly correlated with measures of avoidance. ${ }^{21,22,25}$ As suggested, pain avoidance and pacing to reduce pain may share some features. Pacing to reduce pain could be understood as a 'reactive' strategy to alleviate pain. ${ }^{4}$ In contrast, a kind of pacing in which patients deliberately display a preplanned strategy aimed at increasing activity levels is likely to obtain different results. ${ }^{28}$ It may also be the case that patients who practice more reactive pacing strategies also avoid pain. ${ }^{4}$ Neither the APS pacing to reduce pain subscale nor the APS pain avoidance subscale were associated with the criterion variables, except for a low positive association between pain avoidance and activity impairment. It appears to be the case that when avoidance and pacing are monitored according to pain fluctuations they are not associated with patient adjustment.
In contrast, pacing to increase activity levels and to conserve energy for valued activities had positive moderate correlations with daily functioning, positive low correlations with positive affect, and negative low correlations with negative affect and activity impairment. Although the associations are not very strong, the results suggest that these 2 preplanned forms of pacing are adaptive and help people with chronic pain to function better. ${ }^{28}$ These results contradict previous findings suggesting that pacing is associated with increased disability ${ }^{4}$; however, the results are in line with another study $^{26}$ that found that pacing predicted lower levels of physical impairment. On the basis of our results, it is suggested that different pacing behaviors should be distinguished according to their goals; this distinction would clearly contribute to clarifying the association between pacing and adjustment to chronic pain.

The study found that persistence was the activity pattern that had the greatest degree of independence from the other patterns. The only exceptions were the low negative correlation between the APS taskcontingent persistence subscale and the 2 APS avoidance subscales, and the moderate negative correlation between the APS task-contingent persistence subscale and the POAM-P avoidance subscale, which may indicate that individuals who, despite pain, practice behavioral persistence to finish tasks or activities, are less prone to avoid pain and activity.

The APS task-contingent persistence subscale had moderate negative correlations with negative affect and activity impairment and a positive moderate correlation with daily functioning; it also had a high positive correlation with positive affect, and thus it is suggested that this is the most adaptive activity pattern. This result is in line with a previous study. ${ }^{22}$ It is striking that this is the activity pattern with the highest association with positive affect; this result could be explained by motivational mechanisms: People carry on with an activity because of the value of the activity and this behavior is associated with a sense of control, self-efficacy, and positive affect. Similarly, a study in patients with low back pain found that endurance behavior and positive mood were associated with increased feelings of control over pain $^{32}$ and subjectively reported quality of life. ${ }^{35}$ It is also noteworthy that whereas high task-contingent persistence was associated with lower negative affect, high excessive persistence was associated with higher negative affect. These results may be related to the distinction made in the avoidance-endurance model between a distress-endurance response and a eustressendurance response. ${ }^{15}$ Kindermans et $\mathrm{al}^{22}$ also found that excessive persistence was strongly associated with high depression scores. In this sense, excessive persistence could be understood as a reaction to intense negative affect, in which patients try to counteract high emotional discomfort by engaging in an excessive rate of activity. The use of exercise as an affect-regulation strategy has been postulated as a mechanism involved in other problems in which an excessive rate of activity has been observed, such as anorexia nervosa and bulimia nervosa ${ }^{11}$ and exercise addiction. ${ }^{41}$ In fact, it has been 
proposed that patients with high levels of excessive persistence might benefit from cognitive-behavioral treatments, including response prevention strategies. ${ }^{22}$ Because of the correlational nature of the design, the alternative explanation cannot be ruled out and it could be the case that excessive activity creates negative affect. Future research should investigate the relationship between excessive persistence and negative affect.

The 3 types of persistence were positively associated with daily functioning and negatively associated with activity impairment, although the magnitude of the correlations differed. Because the correlations were not high, it is at least suggested that the 3 types of persistence are not associated with greater disability. Kindermans et $\mathrm{al}^{22}$ obtained results that were similar to ours in relation to task-contingent persistence; nevertheless, their study showed that excessive persistence was associated with greater disability. Finally, it should be emphasized that no correlations or only low correlations were found between pain and all of the APS subscales. The absence of an association between the APS activity patterns and pain intensity could be explained by the fact that the participants in study 2 had been experiencing pain for a considerable number of years (median pain duration was 14.69 years). It has been found that, when pain duration is sufficiently long, there is a certain degree of independence between what patients do to cope with pain (except for catastrophizing) and the pain intensity that they are experiencing, whereas there is an association between coping and disability and affect. ${ }^{12}$ This result has relevant clinical implications because, regardless of pain intensity, patterns of behavior that are related to better adjustment to chronic pain can be taught.

This study has some limitations. First, the number of participants with fibromyalgia outnumbered the participants with other rheumatic diseases. This difference was particularly marked in study 1 and may have influenced the results, although preliminary analyses found no differences in means between the 2 groups in any of the APS or POAM-P subscales. Second, although the internal consistency of the APS subscales in study 1 was not very high, it was considerably higher in study 2. However, if the number of items is taken into account, the indexes were adequate because scales with fewer than 10 items are still adequate providing that $\alpha$ is $>.60 .^{24}$ In addition, because the 3 APS subscales were highly correlated, it could be argued that there is little point in distinguishing 3 dimensions in pacing. Nevertheless, the 8-factor structure was superior to the 6-factor structure and it is particularly relevant that the 3 subscales showed different patterns of relationships with the other APS and POAM-P subscales and with the criteria. Third, only 3 pacing behaviors have been included in the APS, that is, the ones with the widest consensus and the least potential overlap with other patterns of behavior; nevertheless, a more inclusive approach could have been followed. Finally, it could be argued that there is potential overlap between the activity avoidance and the excessive persistence scales and the outcomes (disability and negative affect), because the items of these scales include nega- tive consequences (eg, "I have tried to do too much and felt even worse as a result" or "I have put parts of my life on hold"). Nevertheless, if these scales had been measuring the same constructs, unacceptably high correlation coefficients would have been expected, which was not the case. ${ }^{22}$

According to the results, pacing training should emphasize the goal of pacing behaviors. Rather than using pacing to reduce their pain, patients should be taught to use pacing to enable them to carry out their valued activities. The inverse association found between the APS task-contingent persistence subscale and the avoidance subscales, as well as its association with better adjustment to chronic pain, lends support to therapeutic approaches that emphasize the importance of 'doing despite pain,' such as acceptance and commitment therapy. $^{13}$

Future research should investigate the validity of the dimensions of the APS activity patterns by studying if their relationship with measures of psychosocial functioning differs from those of existing measures of activity patterns. The conceptualization of the dimensions of the activity patterns remains a controversial issue because the patterns actually performed by people are not only the result of their habitual style, but also of contextual factors with motivational elements playing a central role. The APS goes a step further than previous instruments because some of its dimensions include elements related to the purpose of the activity pattern, such as task-contingent persistence, pain-contingent persistence, excessive persistence, or pacing related to different purposes (increasing the activity level, conserving energy for valued activities, or reducing pain). Nevertheless, future research should test the construct validity of these dimensions not only by relying on self-reports, but also by using objective measures. $2,3,37,38$

In summary, although further research is needed, this study provides evidence that the APS, which assesses 8 activity patterns with a relatively low number of items, is a promising instrument for clinical practice and research. This instrument could be useful in research conducted from a self-regulation perspective in which the goals of avoidance, persistence, and pacing behaviors are considered to be the key factors that influence disability and well-being, rather than their being considered intrinsically adaptive or maladaptive. ${ }^{38}$ This distinction between functional and dysfunctional forms of avoidance, persistence, and pacing could contribute to refining the treatment instructions aimed at the regulation of the patient's activity and to providing a more individualized approach.

\section{Acknowledgments}

The Fibromyalgia Association of Marbella, Fibromyalgia and Chronic Fatigue Syndrome Association of Málaga, Rheumatoid Arthritis Association of Málaga, and the Agencia Sanitaria Costa del Sol collaborated in this study. 


\section{References}

1. Akaike H: Factor analysis and AIC. Psychometrika 52: 317-332, 1987

2. Andrews NE, Strong J, Meredith PJ: Avoidance or incapacitation: A discussion on definition and validity of objective measures of avoidance, persistence and overactivity. Clin J Pain 31:670-672, 2015

3. Andrews NE, Strong J, Meredith PJ: Overactivity in chronic pain: Is it a valid construct? Pain 156:1991-2000, 2015

4. Andrews NE, Strong J, Meredith PJ: Activity pacing, avoidance, endurance, and associations with patient functioning in chronic pain: a systematic review and meta-analysis. Arch Phys Med Rehabil 93:2109-2121, 2012

5. Bagraith KS, Strong J, Sussex R: Disentangling disability in the fear avoidance model: More than pain interference alone. Clin J Pain 28:273-274, 2012

6. Bentler PM: EQS 6 Structural Equations Program Manual. Encino, CA, Multivariate Software, Inc, 2006

7. Bentler PM: Comparative fit indexes in structural models. Psychol Bull 107:238-246, 1990

8. Bentler PM, Bonnet DG: Significance tests and goodness of fit in the analysis of covariance structures. Psychol Bull $88: 588-606,1980$

9. Cane D, Nielson WR, McCarthy M, Mazmanian D: Painrelated activity patterns: Measurement, interrelationships, and associations with psychosocial functioning. Clin J Pain 29:435-442, 2013

10. Cohen JW: Statistical Power Analysis for the Behavioral Sciences, 2nd ed. Hillsdale, NJ, Lawrence Erlbaum Associates, 1988

11. Davies RR: The treatment of compulsive physical activity in anorexia nervosa lacks a conceptual base. Adv Eat Disord 3:103-112, 2015

12. Esteve $R$, Ramírez-Maestre C, López-Martínez AE: Adjustment to chronic pain: The role of pain acceptance, coping strategies, and pain-related cognitions. Ann Behav Med 33:179-188, 2007

13. Hann KE, McCracken LM: A systematic review of randomized controlled trials of acceptance and commitment therapy for adults with chronic pain: Outcome domains, design quality, and efficacy. J Context Behav Sci 3:217-227, 2014

14. Hasenbring $\mathrm{M}$ : Attentional control of pain and the process of chronification. Prog Brain Res 129:525-534, 2000

15. Hansenbring M, Hallner D, Klasen B, Stretlein-Böhme I, Willburger $\mathrm{R}$, Rusche $\mathrm{H}$ : Pain-related avoidance versus endurance in primary care patients with subacute back pain: Psychological characteristics and outcome at 6-month follow-up. Pain 153:211-217, 2012

16. Hu L, Bentler PM: Cutoff criteria for fit indexes in covariance structure analysis: Conventional criteria versus new alternatives. Struct Equ Modeling 6:1-55, 1999

17. Hu L, Bentler PM: Fit indices in covariance structure modelling: Sensitivity to underparameterized model misspecification. Psychol Meth 3:424-453, 1998
18. Jensen MP, Turner P, Romano JM, Fischer LD: Comparative reliability and validity of chronic pain intensity measures. Pain 83:157-162, 1999

19. Jensen MP, Turner JA, Romano JM, Strom SE: The Chronic Pain Coping Inventory: Development and preliminary validation. Pain 60:203-216, 1995

20. Jöreskog KG, Sörbom D: Lisrel 8: Structural Equation Modeling with the SIMPLIS Command Language. Hillsdale, MI, Scientific Software International, 1993

21. Karsdorp PA, Vlaeyen JW: Active avoidance but not activity pacing is associated with disability in fibromyalgia. Pain 147:29-35, 2009

22. Kindermans HP, Roelofs J, Goossens ME, Huijnen IP, Verbunt JA, Vlaeyen JW: Activity patterns in chronic pain: Underlying dimensions and associations with disability and depressed mood. J Pain 12:1049-1058, 2011

23. Kline RB: Principles and Practice of Structural Equation Modeling, 3rd ed. New York, NY, Guilford Press, 2005

24. Loewenthal KM: An Introduction to Psychological Tests and Scales, 2nd ed. London, Psychology Press, 2001

25. McCracken LM, Samuel VM: The role of avoidance, pacing, and other activity patterns in chronic pain. Pain 130: 119-125, 2007

26. Nielson WR, Jensen MP, Hill ML: An activity pacing scale for the chronic pain coping inventory: Development in a sample of patients with fibromyalgia syndrome. Pain 89: $111-115,2001$

27. Nielson WR, Jensen MP, Karsdorp PA, Vlaeyen JW: A content analysis of activity pacing in chronic pain: What are we measuring and why? Clin J Pain 30:639-645, 2014

28. Nielson WR, Jensen MP, Karsdorp PA, Vlaeyen JW: Activity pacing in chronic pain: Concepts, evidence, and future directions. Clin J Pain 29:461-468, 2013

29. Phillip HC, Rachman S: The role of activity pacing. In: Phillips HC, Rachman S (eds): The Psychological Management of Chronic Pain: A Treatment Manual. New York, NY, Springer, 1996, pp 174-184

30. Ramírez-Maestre C, Esteve R: A new version of the Impairment and Functioning Inventory for patients with chronic pain (IFI-R). PM R 7:e1-e8, 2015

31. Ramírez-Maestre C, Valdivia Y: Evaluación del funcionamiento diario en pacientes con dolor crónico [The assessment of daily functioning in chronic pain patients]. Psicol Conduct 11:283-291, 2003

32. Rusu A, Hansenbring M: Multidimensional Pain Inventory derived classifications of chronic pain: Evidence for maladaptive pain-related coping within the dysfunctional group. Pain 134:80-90, 2008

33. Sandín B, Chorot $P$, Lostao L, Joiner TE, Santed MA, Valiente RM: Escalas PANAS de afecto positivo y negativo: Validación factorial y convergencia transcultural [The PANAS scales of positive and negative affect: factor analytic validation and cross-cultural convergence]. Psicothema 11: 37-51, 1999

34. Sandín B, Valiente RM, Chorot P: Instruments for the assessment of psychosocial stress. In: Sandín B (ed): Psychosocial stress: Concepts and clinical consequences. Madrid, Klinik, 2008, pp 275-358 


\section{Esteve et al}

35. Scholich SL, Hallner D, Wittenberg RH, Rusu A, Hasenbring MI: Pilot study on pain response patterns in chronic low back pain. The influences of pain response patterns on quality of life, pain intensity and disability. Schmerz 25:184-190, 2011

36. Spence M, Moss-Morris R, Chalder T: The Behavioral Responses to IIIness Questionnaire (BRIQ): A new predictive measure of medically unexplained symptoms following acute infection. Psychol Med 35:583-593, 2005

37. Van Damme S: Avoidance and persistence: Capacity or motivation? Clin J Pain 31:843-844, 2015

38. Van Damme S, Kindermans H: A self-regulation perspective on avoidance and persistence behavior in chronic pain: New theories, new challenges? Clin J Pain 31:115-122, 2015

39. Vlaeyen JW, Linton SJ: Fear-avoidance and its consequences in chronic musculoskeletal pain: State of the art. Pain 85:317-332, 2000

40. Watson D, Clark LA, Tellegen A: Development and validation of brief measures of positive and negative affect: The PANAS scales. J Pers Soc Psychol 54: 1063-1070, 1988

41. Weinstein $A$, Weinstein $Y$ : Exercise addiction-diagnosis, bio-psychological mechanisms and treatment issues. Curr Pharm Des 20:4062-4069, 2014

42. World Health Organization: International Classification of Functioning, Disability and Health: ICF. Geneva, Switzerland, World Health Organization, 2001 